\title{
Afectividades y desplazamientos escriturales en la obra de Nona Fernández*
}

\section{Affectivities and Writing's Displacements in the Work of Nona Fernández}

\begin{abstract}
Resumen
La obra de Nona Fernández ha sido catalogada dentro de que se conoce como "generación de los hijos" para referirse a aquellas narraciones de autores que eran niños/as durante la dictadura chilena. Desde una mirada de la narración hacia los géneros autobiográficos y autoficcionales que han sido atravesados por la ficción para cuestionar las certezas construidas y las fallas de la memoria, se analizará la obra de la escritora chilena Nona Fernández para entender de qué forma el proceso de escritura, su relación con el evento y los procesos de subjetivación de los personajes. Nos centraremos principalmente en dos obras las cuales tienen un hilo de continuidad narratológica e histórica, como son Space Invader (2013) y La dimensión desconocida (2016), ambas obras unidas por el terribles acontecimientos sucedidos en la dictadura chilena. Todo narrado en un tiempo cíclico, como una dimensión desconocida, viviendo en el presente los horrores que creíamos pasado.
\end{abstract}

Palabras claves Nona Fernández; autoficción; escritura; narrativa chilena.

\footnotetext{
"Artículo publicado bajo el patrocinio del FONDECYT de Iniciación No 11170556: "Visualidades, imaginarios territoriales y cuerpos comunitarios: hacia nuevas prácticas textuales de escritoras chilenas contemporáneas". Agradecimientos al grupo de investigación de Literatura y Escuela (LyE) de la Universidad Autónoma de Chile.
} 


\begin{abstract}
Nona Fernández's work has been catalogued within what is known as the "generation of the children" to refer to those narrations by authors who were children during the Chilean dictatorship. The work of the Chilean writer Nona Fernández will be analyzed to understand how the writing process, its relationship with the event and the processes of subjectivation of the characters, from a narrative perspective towards the autobiographical and autofictional genres, have been crossed by fiction to question the constructed certainties and the failures of memory. We will focus mainly on two works which have a thread of narratological and historical continuity, such as Space Invader (2013) and La dimensión desconocida (2016). Both works are related by the terrible events that happened during the Chilean dictatorship. Everything narrated in a cyclical time, like an unknown dimension, living in the present the horrors that we thought were past.
\end{abstract}

Keywords Nona Fernández; Autofiction; Writing; Chilean fictions.

Algo inquietante circula en este lugar, puedo sentirlo. Es como si las construcciones tuvieran conciencia de lo que estoy narrando y frente al recuerdo el paisaje se quedara mudo intentando dar espacio a lo que nuestros ojos no puedan ver, a lo que aparentemente ya no está.

("La dimensión desconocida" p. 139)

La década de los '90 en Chile se caracterizó por un silencio "democrático" que modificó las prácticas de censura heredadas de la dictadura instalando lo que José Salomon llama "retórica del consenso". Con este término define un ejercicio público de enunciación "no solo con el objetivo de aplacar la persistente menaza militar, sino también de normalizar la vida cotidiana, en una construcción permanente de homogeneidad social y omisión de diferencias y alternativas" (18). La postdictadura, por lo tanto, ha administrado bajo esta forma retórica la regulación de todos los espacios públicos por medio de una despolitización de la 
palabra que evite, bajo cualquier circunstancia, el debate, el intercambio de ideas y otras formas disidentes de opinión.

No es de extrañar que aquellos que construyeron estos consensos, aquellos que fueron "cómplices y complacientes"1 de las políticas dictatoriales, ahora argumentan a través de los medios de comunicación ${ }^{2}$ que no fueron capaces de ver la desigualdad, la desconfianza, indignación de los que no tuvieron participación en este reparto de la enunciación. El estallido social que se vivió en Chile en octubre del 2019 expuso en forma descarnada una serie de reclamos que se oían desde hace bastante tiempo, pero que se hicieron oídos sordos. El resultado fue la masiva la manifestación de los excluidos ${ }^{3}$ que salen a las calles para exigir las demandas que fueron prometidas hace más de treinta años. A más de un año de las movilizaciones, las consecuencias están a la vista: se ha mantenido el toque de queda -ahora por "razones sanitarias"-, resoluciones judiciales con respecto a los muertos en los saqueos aún sin resolver, víctimas de trauma ocular o ceguera, ${ }^{4}$ abusos sexuales de parte de la policía sin resultado judicial y jóvenes que aún están detenidos sin juicios. Por ello, las Humanidades, específicamente desde la literatura, no debe permanecer ajeno a los acontecimientos, como afirma Patricia Espinosa "Nadie puede quedar inmune al ver el dolor de la gente y el sufrimiento, y mucho menos la violencia desatada del poder. Esto ya no se trata de un Yo, sino de todos. Y creo que ningún arte, y menos la literatura, va a ser el mismo después de este estallido".

${ }^{1}$ Cito la afirmación de Michael Lazzara: "All these complicit civilians, in their own ways, have been "obedient" either to the dictatorship's violations of humans rights or the inequalitygenereting neoliberal model the Pinochet regime imposed, or both" (6)

2 "Medios de comunicación", así en plural, es paradójico. Con el anuncio del cierre de "La Cuarta" y la reducción del papel de "La Tercera", Chile tiene un solo diario, "El Mercurio". En una conversación con Diamela Eltit, me explica que este escenario no había ocurrido en Chile desde la fundación de la Aurora de Chile, es decir, la prensa chilena tiene un solo diario nacional que dirige la información. A pesar de los esfuerzos de la prensa independiente, esta empresa es la que administra todas las filiales de las prensas más locales.

${ }^{3}$ Me refiero no sólo a aquellos que han permanecido al margen social y económico, sino también a quienes han habitado el margen cultural por lo adaptarse a los consensos.

${ }^{4}$ Como los casos de Gustavo Gatica y Fabiola Campillay que se han convertido en emblemáticos. Ver documental de Daniel Miranda Acuña: "Los ojos del estallido": https://www.youtube.com/watch?v=UTmPPYwtpdU 
Se trata entonces de mirar hacia atrás y releerlo todo para rebuscar las partes más cruentas de las crisis.

En este proceso de relectura, hemos seleccionado a la escritora chilena Nona Fernández, quien tiene una vasta trayectoria artística como escritora, guionista, actriz y activista cultural. Su obra se encuentra inserta en una propuesta narrativa que se viene gestando desde hace más dos décadas en la literatura latinoamericana. Sus inicios se encuentran en los análisis que los estudios culturales y subalternos realizan sobre cómo las formas populares de la cultura de masas han penetrado en los textos de ficción, pero que fueron rechazados porque no contaron con la "bendición de la alta literatura", como sucedió con las novelas de Manuel Puig La traición de Rita Hayworh (1968) y Boquitas Pintadas (1969), ${ }^{5}$ poniendo en juicio el rigor de lo estrictamente literario. Sin embargo, la obra de Nona Fernández tampoco se adscribe a las producciones referenciales del testimonio en su forma más clásica, sino más bien presenta las condiciones de verosimilitud que legitiman la estrecha relación entre la experiencia y el acontecimiento histórico que se desea testimoniar. En otras palabras, los informes judiciales, testimonios, relatos de las comisiones de Derechos Humanos presentados en su propio lenguaje legal y periodístico son expuestos en las obras con todo el horror y en su forma más cruda, haciendo que la literatura deba reflexionar sobre los acontecimientos no para escenificar los "hechos", sino para hacer emerger lo tremendo. La propuesta de Nona Fernández es precisamente ingresar a esa dimensión horriblemente desconocida, como se titula una de sus obras, a través de la imaginación como forma de reponer lo olvidado por la memoria. Se trata de hacer, por medio de la escritura, que los cuerpos aparezcan y los nombres no queden sólo en una ficha legal. Son cuerpos que Judith Butler ha trabajado bajo las figuras de lo abyecto, de

${ }^{5}$ A partir de Boquitas Pintadas se inicia un desarrollo paratextual e hipertextual que se moviliza en dos vías. Por un lado, las referencias a la visualidad del cine hollywoodense (radioteatros, música popular como el tango y el bolero) que funcionan como elementos de representación de todas las culturas que forman parte de la narración. Por otro lado, una serie de textos referenciales (cartas, diarios personales, fragmentos de noticias, documentos oficiales) que ayudan al lector a formar la historia. Sin embargo, lo más importante es que esos hipertextos no sólo conforman el plano psicológico de la novela, sino también el social y político. 
vidas que no son embestidas con las características de lo humano, de vidas que no son reconocidas como tales y que por lo tanto no son dignas de duelo, vidas que no son inteligibles como vidas. ${ }^{6}$

La obra de Fernández ha sido catalogada dentro de que se conoce como "generación de los hijos" para referirse a aquellas narraciones de autores que eran niños/as durante la dictadura chilena, ${ }^{7}$ inflexionando la narración hacia los géneros autobiográficos y autoficcionales atravesados por "la ficción para desarmar algunas certezas, para evidenciar las fallas y huecos de la memoria y para introducir las posibilidades de la imaginación"8 (Basile 34). Para Lorena Amaro, la obra de Fernández pertenece a lo que define como "autoficción” que se caracteriza por "la inestabilidad de la narración y la incertidumbre respecto de una imagen originaria o fundamente" (21). En esta misma línea, Rodrigo Cánovas, desde la postura del "giro subjetivo" de Sarlo, propone diversas escenas autobiográficas 9 en la narración chilena. La "escena de la escritura" destaca a aquellas escrituras del yo que contienen un registro intermedial y la hibridez discursiva, definiendo a la escritura desde sus soportes que "nos permitan hablar del cuerpo, tanto en el sujeto (gestos, voces, estructura sicosomáica) como en la escritura (letra, significante, materialidad de las formas)" (92). Otros críticos coinciden en leer la obra de Fernández desde la “autoficción” (Pastén 135) o destacando los aportes extraliterarios, como es el caso del documental "Habeas Corpus" en La dimensión desconocida, que no se nombra,

${ }^{6}$ Butler afirma que el poder militar ha intentado maximizar 1 precariedad que toda vida humana contiene. Esta "administración" de la precariedad es material, ya que obran sobre los cuerpos, y conceptual, ya que se basa en la construcción de todo un aparataje político, "puesto que aquellos cuyas vidas no se "consideran" susceptibles de ser lloradas, y, por ende, de ser valiosas, están hechas para soportar la carga de hambre, del infraempleo, de la desemancipación jurídica y de la exposición diferencial a la violencia y la muerte" (45)

${ }^{7}$ Entre otros autores se encuentran: Alejandro Zambra, Rafael Gumucio, Alejandra Costamagna, Andrea Jeftanovic, Alvaro Bisama, Diego Zuñiga.

${ }^{8}$ Basile se refiere a la "segunda generación" de HIJOS en Argentina que han sido víctimas y partícipes de la historia reciente.

${ }^{9}$ Cánovas propone tres escenas chilenas que tienen como eje la figura de los fantasmas que buscan un origen. Las "escenas familiares" son aquellas reclaman por instaurar una casa paterna donde se ha perdido un tronco masculino débil. Es la mirada de la orfandad. La siguiente es la "escena comunitaria" que se define desde un "nosotros" para elaborar lazos primordiales. Finalmente, la "escena de escritura", que presenta de forma más o menos concreta el género autobiográfico, enfatizándolos soportes materiales y la hibridación de las formas. 
pero se reconoce en su descripción, haciendo coincidir la relación entre "la narradora y la autora empírica" (Carrasquer 28) o destacando la "legitimidad de la reminiscencia" (Miranda Mora 259) como otra forma de testimoniar.

Para ingresar al análisis de la obra de Nona Fernández, es necesario preguntarse ¿cómo la escritura de Fernández evidencia los retazos de una realidad sin un principio estructurante o totalizador?, ¿De qué forma estos "archivos escriturales" reviven esa historicidad por medio de la experiencia? Y, por último, ¿cómo se configuran las subjetividades en estos procesos paradojales en lo que llamaremos el "pacto de ambigüedad" en la construcción del mundo ficcional? De este modo, el objetivo de este artículo es analizar el proceso de escritura, su relación con el evento y los procesos de subjetivación de los personajes en la obra de Nona Fernández. ${ }^{10}$ En este artículo, nos centraremos principalmente en dos obras las cuales tienen un hilo de continuidad narratológica e histórica, como son Space Invader (2013) y La dimensión desconocida (2016). Es necesario señalar que la obra de Fernández se construye como una genealogía del terror, que va rescatando y replicando diferentes escenas de violencia como el "Caso Degollados" en Space Invader, donde un coro de voces yuxtapuestas de niños y niñas compañeros de colegio, recuerdan y sueñan a una compañera relacionada con el caso. En Chilean Electric (2015) donde también desfilan cuerpos maltratados, como el de un niño de catorce años, golpeado por los carabineros, con un ojo fuera de su cara, en la plaza de Armas, en 1984. Todo narrado en un tiempo cíclico, como una dimensión desconocida, viviendo en el presente los horrores que creíamos pasado.

Las obras se elaboran a través de diferentes formatos de la cultura popular en la década de 80, como son la famosa serie de televisión, como metonimia de las desapariciones y el "Space Invader", un juego de Atari muy popular en aquellos años, para describir una ciudad invadida, no por alienígenas (como lo creyó alguien

${ }^{10}$ Entre sus textos narrativos se encuentran Mapocho (2002), Av. 10 de Julio Huamachuco (2007), Fuenzalida (2012), Space invaders (2013), Chilean Electric (2015), La dimensión desconocida (2016), Preguntas frecuentes (2020). Obras de dramaturgia como El Taller (2012) y Liceo de niñas (2015) y el ensayo Voyager (2019). Además, cuenta con un amplio repertorio de guiones y adaptaciones de serie de televisión que serán importantes para nuestro análisis. 
durante el estallido social chileno), sino por las fuerzas militares. Además, encontramos reminiscencias de otros elementos de la cultura popular como la famosa película "Los Cazafantasmas", que en La dimensión desconocida era utilizada de música de fondo en los secuestros o el programa "Juegos de Mente" donde un animador pone a prueba la capacidad mental del espectador para explicar los misterios del cerebro humano. ${ }^{11}$ Todo esto entretejido con reportaje periodístico, el relato autobiográfico de sueños, el formato de archivo y confesión.

Este acoplamiento narrativo es una de las características más originales de la propuesta estética de Nona Fernández que se produce por medio de dos formas: una, de la imagen y escritura; y la otra, la del residuo corporal y material, configuradas desde una espacialidad centrífuga, es decir, hacia la ciudad, o centrípeta, hacia los interiores. La relación entre visualidad y escritura es movible, líquida como la figura del río en su primera novela llamada precisamente Mapocho. La segunda se erige desde los restos, ya sea desechos y restos corporales. Ambas formas conjugan una memoria histórica que resurge de los escombros no como desecho, sino como memoria latente. Se trata de una especie de registro despedazado que emerge por la relación entre el archivo y la experiencia. Es lo que Florencia Garramuño llama "la experiencia opaca" para referirse a "un tipo de escritura que, a pesar de hacer evidentes los restos de lo real que forman el material de sus exploraciones, se desprende violentamente de la pretensión de pintar una "realidad" completa regida por un principio de totalidad estructurante"(19).

\section{Escenas de escritura}

Las colectividades definen su modo de actuación y representación del presente negociando con su pasado para permitir elaborar una forma de identidad o identificación que configure una especie de comunidad. Ciertos acontecimientos

${ }^{11}$ El capítulo relatado de La dimensión desconocida se llama "ceguera por desatención" donde el cerebro ve lo que quiere ver, como metáfora explícita de la zombificación de la postdictadura. 
históricos, figuras públicas, objetos culturales forman parte de una representación de la realidad que se presenta como una propuesta de interpretación sobre los hechos, como sucede con la obra de Nona Fernández, donde encontramos historias procedentes de acontecimientos verídicos que se narrativizan por medio de un procedimiento que combinan técnicas y estrategias tanto de la narrativa como de los géneros no ficcionales. Es lo que Alberca denomina "autoficción"12 donde el "yo" es un recurso retórico con plena conciencia de su ficcionalidad que intenta "abrir un espacio de invención y creación ciertamente peculiar en el intersticio de lo ficticio y lo factual, justo en el punto en que ambos se oponen y se distinguen" (48). La ubicación en este límite le permite al autor/a autoficcional poner en escena $^{13}$ en el mismo texto la tensión entre ambas estrategias narrativas que se desarrollan en forma paralela y con múltiples imbricaciones. Los procedimientos de la narración emergen desde el recuerdo repentino, la introspección y algún objeto que gatilla el recuerdo. Según Martínez Rubio, existen diferentes formas de indagación para entregar un sentido propio al acontecimiento de la escritura ${ }^{14} \mathrm{y}$ crear el "efecto de autenticidad" necesario para formar el lazo entre el autor/a y el

${ }^{12}$ En los últimos años ha habido un desarrollo más profundo acerca de los conceptos de fícción, autoficción, narraciones del yo. Para un análisis más detallado sobre este concepto, véase: Las formas de la verdad Investigación, docuficción y memoria en la novela hispánica (2000-2015) de José Martínez Rubio; La obsesión del yo. La auto(r)ficción en la literatura española y latinoamericana de Vera, Schlickers Luengo. Leonor Arfuch: La vida narrada. Memoria, subjetividad y política (2018) y El espacio biográfico. Dilemas de la subjetividad contemporánea (2010). En Chile, sobre las narrativas del yo o autoficción ver Lorena Amaro Castro: La pose autobiográfica. Ensayos sobre narrativa chilena (2018), Rodrigo Cánovas: Escenas autobiográficas chilenas (2019), José Salomon Gebhard: Falso subalterno. Testimonio y ficción en la narrativa chilena de postdictadura (2020).

${ }^{13}$ En el caso de Nona Fernández, el significado de "poner en escena" es doble, ya que performativiza las obras narrativas demostrando su relación intrínseca son sus obras de teatro como El taller (2012), Liceo de niñas (2015) el trabajo dramatúrgico de Fernández merece un tratamiento más profundo, el cual dejaremos pendiente para otra investigación.

${ }^{14}$ Entre estos procedimientos se encuentran: la rememoración, centrada en un narrador/a en primera persona que alterna la voz del presente para recuperar el pasado de manera crítica y concienzuda, por lo que la voz presente tiene un momento crítico que exige la revisión del acontecimiento. La reconstrucción requiere de un punto de apoyo externo, ya que apela a la memoria como desconocimiento, por esto exige una voz otra con la que pueda reconstruir el pasado. La revelación es una investigación a la inversa, ya que el personaje recibe información de manera involuntaria. Cfr. Martínez Rubio, José. Las formas de la verdad. Investigación, docuficción y memoria en la novela hispánica (2000-2015). 
lector/a para provocar una disposición hacia el otro, o en palabras de Jean-Luc Nancy, el clinamen, es decir, "una inclinación o una disposición del un hacia el otro, del uno por el otro o del uno al otro" (17).

Observamos en las obras una disposición estructural que es fundamental para comprender los procesos de subjetivación y las identidades narrativas que veremos más adelante. Por esto, nos centraremos en la dimensión enunciativa de la producción del discurso. El primer aspecto que debemos considerar es que nos encontramos con una narración perturbadora que utiliza estrategias complejas y lúdicas para desconcertar al lector/a. La perturbación no es una molestia para el lector, sino todo lo contrario, ya que provoca el deseo de búsqueda e inmersión en la trama para buscar, junto con el narrador/a, aquello que se mantiene oculto. En Space Invader nos encontramos con un popular juego de Atari de los años ' 80 como elemento catalizador del recuerdo. No es casual que se recurra a un juego, ya que la macro estructura de la obra coincide con el procedimiento de indagación de la realidad. Se trata de la rememoración de un evento donde la narradora se desdobla para evocar el año 1980:

En un liceo del barrio Avenida Matta, una niña de diez años entra de la mano de su papá. Afuera, en la calle, aún quedan los restos de una celebración que dejó algunos panfletos, botellas vacías y basura desperdigada por la vereda. La nueva Constitución propuesta por la Junta Militar fue aprobada por amplia mayoría. (19)

La voz se moverá entre esos dos tiempos, el de la niña en el pasado y la voz presente, donde los acontecimientos se develarán de manera concienzuda en un momento crítico, como afirma la voz del presente "A veces soñamos con ella. Desde nuestros colchones desperdigados por Puente Alto, La Florida, Estación Central o San Miguel, desde las sábanas sucias que delimitan nuestra ubicación 
actual" (21). La voz presente, por medio de la metalepsis, ${ }^{15}$ se involucra verbalmente para revisar un acontecimiento doloroso porque el presente lo exige de alguna forma: "Desde nuestra onírica diversidad podemos concordar que cada uno a su propio modo la ve como la recuerda" (21).

En La dimensión desconocida también se hace uso de una estrategia que detona el recuerdo, pero esta vez por medio de una serie de televisión: "Abramos esta puerta con la llave de la imaginación. Tras ella encontraremos una dimensión distinta. Están ustedes entrando a un secreto mundo de sueños e ideas. Están entrando en la dimensión desconocida" (47). Este relato de la famosa serie de los 80, es el túnel de ingreso a cuatro capítulos, llamados zonas, donde las "zonas de contacto y las de fantasmas" describen el claroscuro de Chile desde donde "el hombre que torturaba", Andrés Valenzuela, alias "El Papudo", va develando sus horrorosos crímenes. El proceso de metalepisis se produce con el ingreso del "hombre que torturaba", Andrés Antonio Valenzuela Morales, agente CNI y torturador, que confesó a la prensa horribles crímenes cometidos durante la dictadura (Memoria Viva). No estamos hablando sólo de un personaje de ficción, sino de un testimonio real.

En ambas novelas, se exponen elementos de la cultura de masas de la época para mostrar y destacar aquello que debe ser "inolvidable", interpelando a la sensibilidad de los lectores para que "tomen posición" frente a los hechos que se han tratado de ocultar por más de tres generaciones. El sentimiento de añoranza de ese "algo" que se recuerda es una "huella afectiva" (Arfuch La vida narrada 142) que trae con más fuerza el recuerdo. Sin embargo, ese recuerdo melancólico de infancia expone además las pesadillas del recuerdo histórico que funden y mezclan en las escenas narradas. Por ello es necesario preguntarse ¿De qué manera el

\footnotetext{
15 "Sustituir la expresión directa por la expresión indirecta, es decir, en dar a entender una cosa por la otra que le precede, sigue o acompaña, que está subordinada o como una circunstancia cualquiera respecto de ella, o finalmente, se une o relaciona con ella de modo que la mente le recuerde inmediatamente". (Genette 9)
} 
recuerdo y la afección impactan en la experiencia, no sólo en la voz narrativa, sino también en el lector implícito?

Esta interrogante, junto al proceso significante de las obras, se resumen en la cita de la obra Chilean Electric (2015): "Iluminar con la letra la temible oscuridad" (93). ${ }^{16}$ La obra utiliza la mirada de cámara donde la narradora vuelve al pasado para enfrentar, mirando en forma directa — como a una cámara - el acontecimiento y así apelar al lector implícito a reflexionar sobre lo acontecido. En ambas novelas, los procedimientos utilizados para provocar la afectación del lector/a es por medio de las tecnologías de los mass media, como son el juego y la serie de televisión que trabajan como gatillantes en la construcción de una memoria personal que se va haciendo colectiva. Los elementos cotidianos - juego de Atari y la serie de tv- se encuentran fijados en el recuerdo de una generación que se define por su materialidad y uso, pero al ser sacados del contexto de tiempo y espacio al que pertenecían, se convierten en perturbadores y críticos. Son entonces de "textos anfibios" (Garramuño 18) que se mantiene en el límite entra la realidad y la ficción que trabajan materiales de "restos de lo real" para hacer aparecer aquello que se mantenía oculto. Por ello Fernández, en el prólogo a la edición de Casa de la Américas de Space Invader, recuerda las luciérnagas de Pasolini:

Yo nunca he visto una luciérnaga. Ni siquiera sé si en Chile existen o si igual que en Italia son parte de un pasado imposible de resucitar. Se me antoja pensar que los marcianitos del Space Invader como esas luciérnagas fosforescentes que iluminaban las noches o más bien los largos y pegajosos días de esos tiempos en que nos tocó ser niños. (8)

\footnotetext{
${ }^{16}$ Esta novela no será abordada en este artículo por razones de extensión. Sin embargo, es una obra de puente o cadena que une Space Invader a La dimensión desconocida por medio de la metáfora de la luz y los fantasmas que intentan mostrar, exponer, iluminar el camino entre pasado y presente.
} 
La luciérnaga, ${ }^{17}$ metonimia de la cámara y la luz al igual que la estrella y los pequeños marcianitos, son elementos que en lo más profundo de la noche "son capaces de captar em menor resplandor, y es la expiración misma de la luz la que todavía nos resulta visible en su estela, por tenue que sea" (Supervivencia 22). Por ello, en la propuesta estética, la escritura no es un medio para comunicar el horror, sino que consiste en la producción de una escena, una imagen que se rearma para ir completando el horror que la constituye en sí misma.

Para Didi-Huberman, la imagen se entiende como subversión porque no se encuentra sólo en el arte, para ello mezcla o "monta" metáforas que provienen de diversas fuentes (pintura, escultura, fotografías), construidas en "el detalle o fragmento" para contextualizarlas en un sentido diferente a la intención primera del autor, haciendo que la metáfora se convierta en un trazo epistemológico sobre el régimen de la imagen y no de esa imagen en particular: "todo depende de lo que se espere de él y de la manipulación a la que se someta" (La imagen 442). De la misma manera, Jacques Rancière (2010) plantea la idea de emancipación al afirmar que la imagen y la palabra, la "imagen pensativa", pueden operan como formas de redistribución de los elementos de la representación. Las obras de Fernández contienen esta idea de imagen fragmentaria, armándose por medio de un montaje de escenas que no rompen con lo cotidiano, ya que vemos a los personajes en su vida normal, pero de pronto son arrastrados a una dimensión desconocida para exponer lo invivible por medio de la elaboración de un texto palimpsesto donde la distinción entre literatura y vida, personajes y sujetos, narradores y yoes, pasado y presente parecen ser irrelevantes. Estrella González de Space Invader y el hombre que torturaba de La dimensión son un medio, un mecanismo para mostrarnos las otras vidas que debieron ser "dignas de ser lloradas" como diría Butler, que le susurran al oído, como fantasmas, a la voz narrativa que se obligue a recordar:

\footnotetext{
${ }^{17}$ No es casual la imagen de la luciérnaga en Fernández. En la cita que utiliza sobre Pasolini, Didi Hubermann relaciona esta desaparición con el resurgimiento de un nuevo fascismo que, en su segunda etapa, no fue advertido por intelectuales y críticos. Momento que denomina de "marchitamiento cultural" (La supervivencia de las luciérnagas 20), dejando claro la relación de esa oscura noche italiana con la chilena.
} 
"Recuerda quién soy, escucha. Recuerda dónde estuve, recuerda lo que me hicieron. Dónde me mataron, dónde me enterraron” (La dimensión 80) ¿De quiénes son estas voces? Los hermanos Boris y Lincoyán Flores, Alonso Gahona Chávez, Lucía Vergara, Arturo Villavela, Sergio Peña... hay más.

La disposición del montaje muestra el conflicto por medio de la paradoja que se entreteje en la historia. En Space Invader la voz narrativa se alterna entre el pasado (voz de la niña) y el presente (voz que recuerda a la niña) para elaborar, puntada a puntada, como el bordado con hilo blanco en la solapa del delantal cuadrillé (23), los acontecimientos horrorosos que se tejen alrededor de la figura de Estrella González y como las voces de los niños de antaño se unen en un sólo sueño. La dimensión desconocida, por otro lado, nos presenta la imaginación como posibilidad de reparar lo olvidado para comprender el pasado. El montaje se inicia por medio de una narración visual donde la voz imagina al hombre que torturaba que después aparecerá en la portada de la revista Cauce. En ambos casos, la estrategia del montaje funciona como "exposición de anacronías" (Didi-Huberman Cuando las imágenes 123) que sacuden el tiempo y el espacio para revelar aquella memoria olvidada.

\section{El archivo de lo real despedazado}

La relación entre archivo y experiencia ha sido compleja, sobre todo desde la mirada testimonial del intelectual letrado que predominó en la década de los ochenta. Para Teresa Basile y Miriam Chiani, la narración testimonial ha tenido un movimiento centrífugo, alimentándose de otras textualidades como la ficción, el humor, los sueños, las pesadillas, los anacronismos:

para 'babelizar' las hablas miméticas del realismo, escapar de las certezas y exhibir los mecanismos lingüísticos fabricadores de la ilusión referencial, así como también para mostrar la lengua dañada por el impacto de la violencia y una gramática dislocada por el quiebre de sentido que toda experiencia traumática acarrea. (14) 
El montaje y desmontaje que analizamos previamente intenta entonces focalizar estos espacios vacíos que la gramática y sintaxis institucional no pueden representar. Por ello, en Space Invader y en La dimensión desconocida vemos fragmentos de historias tejidas por los sueños de los niños, como es el caso de Space o por la imaginación de la voz narrativa en La dimensión que intenta imaginar y recrear mentalmente el escenario para hacer hablar a las cosas: "Imagino y hago testimoniar a los viejos árboles, al cementerio que sostiene mis pies, a los postes de la luz al cableado del teléfono, al aire que circula pesado y no abandona este paisaje. Imagino y puedo resucitar las huellas de la balacera" (La dimensión 141). Estamos frente a una paradoja donde los acontecimientos no tienen testigos, sino una voz sin gramática que intenta hacer testimoniar a los objetos. El proceso de comunicación se desarrolla a través de la puesta en escena del discurso, es decir, desde la performatividad de la enunciación, como afirma Shoshana Felman y Dori Laub, ya que el acto de dar testimonio no consiste sólo en una mera aserción constatativa, sino en una práctica discursiva: "What the testimony does not offer is, however, a complete statement, a totalizable account of those events. In the testimony, language is in process and in trial, it does not possess itself as a conclusion, as the constatation of a veredict or the self-transparency of knowledge" (16). Se puede observar que en ambas novelas el anacronismo es un elemento que une la intención narrativa, pero además fragmenta la historia para desvanecer la fórmula de transparencia del conocimiento absoluto del evento. ${ }^{18}$ Los personajes en ambas novelas se movilizan por esos espacios oníricos para, desde allí, iniciar el recuerdo, como se afirma en Space Invader: "Los sueños son diversos, como diversas son nuestras cabezas, y diversos nuestros recuerdos, y diversos somos y diversos crecimos. De nuestra onírica diversidad podemos concordar que cada uno a su

\footnotetext{
${ }^{18}$ Nona Fernández elabora un excelente uso de una tradición literaria que se abrió con Pedro Páramo de Juan Rulfo, de hacer hablar a las voces de los muertos. En Chile, La Amortajada de María Luisa Bombal resemantiza la voz masculina al hacer hablar a una mujer muerta en su velorio. Cada visita al ataúd es un recuerdo que gatilla un recuerdo, una narración y un comentario. Al igual que en Fernández, la voz la se dirige a un receptor implícito con el cual comparte sueños, imaginaciones y diálogos.
} 
propio modo la ve como la recuerda." (21). Cada recuerdo es un fragmento ${ }^{19}$ que el lector/a debe hilar para tener diferentes perspectivas de los acontecimientos.

En La dimensión desconocida, tenemos cuatro zonas que forman cuatro capítulos. En la "Zona de Ingreso" se encuentra la visita a la inauguración del Museo de La Memoria, donde la voz narrativa se pregunta “¿Cómo se hace la curatoría de un museo sobre la memoria? ¿Quién elige lo que debe ir? ¿Quién decide lo que queda afuera?" (38). El archivamiento, por lo tanto, sitúa la experiencia bajo el signo de la muerte, de la finitud. Sin embargo, este registro se fisura al incluir el testimonio de lo vivido:

Lo que sigue es un momento muy incómodo [...]. Los gritos de Ana y Catalina llegan a remecer a la concurrencia. El recuerdo de los abusos pasados se mezcla con los actuales y por un breve momento no se resigna a la pasividad de lo archivado en el museo. Los gritos de las mujeres despercuden la memoria, lo ponen en diálogo con el presente, lo sacan de la cripta, le dan un soplo de vida y resucitan a esa criatura hecha a retazos, con partes de unos y de otros. Con fragmentos de ayer y de hoy. (39)

El formato de archivo en la novela conjuga la escritura con la visualidad por medio de la ekfrasis, es decir, una representación verbal de una representación visual que, como escritura, hace ingresar en el lenguaje una realidad que supera los límites de la representación:

La primera vez que lo vi fue en la portada de una revista. Era una revista Cauce, de esas que leía sin entender quiénes eran los protagonistas de todos esos titulares que informaban atentados, secuestros, operativos, crímenes, estafas, querellas, denuncias y otros escabrosos sucesos de la época. "Presunto autor de bombazo era jefe local de la CNI", "Degollados siguen penando en La Moneda”, “Así tramaron matar a Tucapel Jiménez”

\footnotetext{
19 Técnica usada también por Gabriel García Márquez en Crónica de una muerte anunciada.
} 
[...] Las imágenes que aparecían en cada ejemplar iban armando un panorama confuso donde nunca lograba hacerme el mapa de la totalidad, pero en el que cada detalle oscuro quedaba rondando en algún sueño. (17)

El archivo se reactualiza en los sueños de la voz narrativa y luego en la experiencia actual de que el pasado aún no pasa. El archivo visual, ya sea la descripción como una "instantánea de la memoria", ya sean las portadas de las revistas, funciona como un residuo opaco que exhibe la historicidad con la experiencia, provocando un poder de afección como forma de producir experiencia al sostener en la presencia del evento en el presente, la posibilidad de una narración de las fracturas que constituyen esa experiencia histórica y personal. Se trata de experiencias que arrancan al sujeto de sí mismo para ubicarla no sólo afuera de la representación, sino afuera de la existencia "vivida". Por eso en las obras de Fernández los personajes son espectros, fantasmas que contienen un vaciamiento y despersonalización radical que desfilan para reclamar sus nombres: "Fijar para que el mensaje no se borre, para que lo que aún no entendemos alguien en el futuro lo descifre. Fijar para anclar a tierra, para dar peso y gravedad, para que nada salga disparado al espacio y se pierda" (74).

\section{Subjetividades narrativas y puestas en discurso}

La experiencia histórica y personal se elabora de múltiples formas en un espacio narrativo por medio de la paradoja, como afirma Arfuch, "el tiempo mismo se torna humano en la medida en que es articulado sobre un modo narrativo" (El espacio biográfico 87). El relato entonces no es sólo la estructuración de los acontecimientos, los espacios, los personajes, etc., sino también la manera en que los cuerpos habitan los espacios y se mueven por esas estructuras que no son fijas. Es lo que conforma la identidad. 
Para Doreen Massey, el espacio es una entidad dinámica y fluida que depende de las relaciones que se instalen en él. Propone un concepto de lugar antiesencialista que reconozca diferencias y subraye las bases de solidaridades potenciales que puedan dar fe de los sujetos que se forman en ella: "En lugar de aceptar y trabajar con las identidades ya constituidas, esta política antiesencialista pone el acento en la constructividad de las identidades y los objetos" (106). Un lugar es un proceso definido por el afuera donde se intercalan diversas identidades e historias con relaciones dinámicas. Los sujetos se construyen en este punto de intersección, por lo que la identidad posee una variedad de discursos, de tiempos y de espacios.

Este dinamismo de las identidades es una cualidad importante en las obras de Fernández, ya que los personajes están elaborados con la técnica del mise en abyme o "construcción en abismo" 20 a través de la repetición de algunos personajes y sus historias. En Space Invader tenemos a Estrella González, la compañera de curso a quien recuerdan. Por medio del estilo indirecto, uno de los niños recuerda a través de a voz narradora una escena:

Riquelme dice que la casa era grande y oscura y llena de puertas cerradas. [...] Abajo estuvo en el comedor y en un living y en un estar con una televisión y un equipo Atari que había sido del hermano de González [...] Riquelme y González jugaron Space Invader durante muchas horas. Las balas verdes fosforescentes de los cañones terrícolas avanzaban rápidas por la pantalla para alcanzar a algún alienígena. Los marcianitos bajaban en bloque, en cuadrado perfecto, lanzando sus proyectiles, moviendo sus tentáculos de pulpo o calamar, pero el poder de González y Riquelme era tremendo y siempre terminaban explotando. (31)

${ }^{20}$ Para Lucien Dallenbach se trata de una técnica que opera al nivel de la narración (verbal y estructuralmente) y también de la ficción, que puede manifestarse de diferentes formas: "simple duplicación", donde el fragmento tiene una relación de reflejo de similitud con el tipo que la contiene; "reduplicación repetida", donde el fragmento reflejado contiene otro fragmento reflejado y así sucesivamente; y por último, la "duplicación aporística", donde el fragmento incluye el trabajo en el que este mismo está incluido (48). 
Esta historia es nuevamente recordada en La dimensión desconocida por medio de la "reduplicación repetida" como un reflejo de espejo en que se relata el accidente sufrido por el papá de Estrella González quien perdió la mano izquierda, para luego, reduplicar el tiempo y el espacio de ambos relatos:

Los años pasaban lentos. El tiempo era pesado con tardes eternas de televisión, de Cine en su casa, de Sábados gigantes, de Perdidos en el espacio, de La dimensión desconocida y de Atari jugando Space Invader en patota. Las balas verde fosforescente de los cañones terrícolas avanzaban rápidamente por la pantalla hasta alcanzar a algún alienígena. Los marcianitos bajaban en bloque, en un cuadro perfecto, lanzando sus propios proyectiles, moviendo sus tentáculos de pulpo o calamar, pero siempre terminaban explotando como la manito izquierda del papá de González. (183-184)

Observamos en ambas escenas el mismo relato del juego de Atari como una autorreferencia que retorna constantemente para narrativizar los acontecimientos ${ }^{21}$ por medio de un juego popular durante los ' 80 que ahora se resignifica desde una serie de televisión por medio de lo que Canclini ha definido como hibridación: "procesos socioculturales en los que estructuras o prácticas discretas, que existían en forma separada, se combinan para generar nuevas estructuras, objetos $\mathrm{y}$ prácticas" (14).

La narración fragmentaria es parte del proceso de subjetivación de la voz narrativa que se posiciona desde un lugar de enunciación movible debido a la repetición. Para Paul Ricoeur, la construcción de una identidad narrativa se elabora diferenciando dos nociones de identidad: la identidad-idem, parte sustantiva de la identidad que corresponde a los atributos concretos de una persona y que

${ }^{21}$ El recurso se repite con una de las voces indirectas de los niños Space Invader como es Fuenzalida (2012), que será el título de otra obra de Nona Fernández. 
permanece en el tiempo; y la identidad-ipse, que configura el "yo" por medio de la narración (ser uno mismo) en relación con "otro" (él mismo). La tesis se centra en el ipse "como el otro" asociado a "sí mismo" como una complementariedad, no sólo comparativa -el "como"-, sino de implicación interlocutora de "sí mismo en cuanto a otro". Este nuevo enfoque propone una subjetividad que construye un discurso y se autodesigna como locutor que puede narrar y accionar en la historia creando su propia identidad para hacerse responsable de sus acciones en ese contexto. Esta relación con el otro es fundamental en la obra de Fernández debido a la construcción palimpsestica que habíamos observado previamente y que está directamente relacionada con la disposición de los personajes y nombres que desfilan en la obra. Tenemos muchos nombres, fechas, cédulas de identidad, historias reales que se asoman y repiten desde diversos puntos de vista en cada texto. Se superponen, se confunden se aglutinan. Sin embargo, la voz narrativa, con conciencia clara de la literaricidad, inicia un proceso de investigación de las víctimas:

Las escenas proyectadas en esta sala son ajenas, pero siempre han estado cerca pisándome los talones. Quizás por eso las considero parte de mi historia. Nací con ellas instaladas en el cuerpo, incorporadas en el álbum familiar que no elegí ni organicé. Mi escasa memoria de aquellos años está configurada por esas escenas. [...]

He dedicado gran arte d mi vida a escudriñar en esas imágenes. Las he olfateado, cazado y coleccionado. He preguntado por ellas, he pedido explicaciones. (La dimensión 65)

A pesar que la modernización capitalista ha triunfado en la fragmentación y el desmembramiento del sujeto, la voz narrativa se niega a convertir esa información y el exceso de imágenes en un consumo vacío y transforma ese exceso de archivo en una intensificación de estados emocionales por medio de la obsesión por la búsqueda y la escritura donde TODO se transforma en testimonio que narra 
desde el afecto, como la afirma la narradora: "He investigado en ellas [las imágenes] hasta el aburrimiento, inventando o más bien imaginando lo que no logro entender $[\ldots]$ he saqueado cada rincón de ese álbum en el que habitan buscando las claves que puedan ayudarme a descifrar el mensaje. Porque estoy segura de que, cual caja negra, contienen un mensaje" (65) La voz narrativa desmonta la separación entre un sujeto de la enunciación y uno del enunciado como entidades diferentes, narrando y actuando, se construye como otro para el otro y, lo más importante, asume responsabilidad respecto a las acciones por medio de una conciencia política. La identidad personal y narrativa son fundamentales, ya que no se ajustan a la primera persona del singular, sino que recurre a una mediación reflexiva que se interesa por todas las voces del discurso.

Para Ricoeur, el proyecto identitario y el eje de la narración se reconoce como una "concordancia discordante" que asume los acontecimientos y las irrupciones imprevistas como momentos constitutivos de la identidad (138), por eso la voz narrativa se empecina en buscar el mensaje. Es necesario subrayar que en esta dialéctica del ídem-ipse, el "anclaje" con el mundo se produce por el cuerpo, que es entendido como "cuerpo entre cuerpos, [que] constituye un fragmento de la experiencia del mundo" (129). La identidad narrativa se basa, por lo tanto, en la diferencia entre estas dos identidades por medio de la interlocución con el otro que se configura en la estructura de una narración permeable que debe admitir los cambios constitutivos de la identidad. Por ello, la estructura de las obras es importante. En Space Invader ingresamos a "Vidas" (primera, segunda, tercera vida) y el final llamado "Game Over", una puesta es abismo del mismo juego. En La dimensión desconocida tenemos cuatro zonas: Zona de Ingreso, Zona de contacto, Zona de Fantasmas y Zona de Escape. Cada una de las "vidas" y "zonas" son escenas que exponen los acontecimientos en un diálogo o un juego (de Atari o de mente) que se repite.

Las obras analizadas reflexionan, de este modo, sobre su propio proceso donde la escritura y la imaginación pueden colaborar en la comprensión del pasado para permitirnos actuar ética y políticamente en el futuro. Sin imaginación no hay 
saber posible, porque con la memoria no alcanza. Como sostiene Jacques Rancière, el arte no es político por los mensaje o sentimientos que comunica acerca del estado de la sociedad, ni por la manera en que representa a los sujetos y a las identidades. Es político en la medida en que sus prácticas producen formas de visibilidad que "reenmarcan" maneras de ser, de sentir y de decir. Es político en la medida en que produce "escenas de disenso", porque la "política consiste en reconfigurar la partición de lo sensible, en traer a escena nuevos objetos y sujetos, en hacer visible lo que no lo era, en transformar en seres hablantes y audibles a quienes sólo se oía como animales ruidosos" (Sobre políticas estéticas 15). La memoria de los niños/as que jugaban Atari y veían la serie de televisión expone para destacar en un sentido ético aquello que queda fuera de los tribunales o de los informes de Derechos Humanos, otorgando a esos nombres un sentido performático que es capaz de sensibilizar y transmitir una responsabilidad comunitaria en la que todos somos parte.

En el último capítulo de la La dimensión desconocida, la voz narrativa se recuerda a sí misma cantando el himno nacional en el liceo, luego vuelve al presente del 2016 para asistir a la ceremonia de José Manuel Parada y Manuel Guerrero ${ }^{22}$ y se encuentra con algunos hijos de las víctimas del hombre que torturaba. El reloj de la dimensión desconocida no conoce tiempo ni espacio y esa ceremonia en la esquina de esa calle, se presentiza: "Creo que ese extraño hilo de coincidencias que hilvana estas dos historias de secuestros, hijos padres y muerte, hilvanó todo en esa época y en esa costura nos adhirió aquí, a esta esquina donde participamos de una ceremonia" (200). La escena finaliza con la voz narrativa y su amiga de infancia tomadas del brazo igual que cuando eran niñas, inhalando el aire para apagar las velas de la conmemoración como si fuera un mantra, como una oración, con los nombres de nuestros muertos para fijarlos en nuestra memoria y grabar en lo que queda de nuestras retinas, sus rostros.

\footnotetext{
${ }^{22}$ Conocido como "El caso degollados".
} 


\section{Bibliografía}

Alberca, Manuel. El pacto ambiguo. De la novela autobiográfica a la autoficción. Madrid: Editorial Biblioteca Nueva, 2007.

Amaro Castro, Lorena. La pose biográfica. Ensayos sobre narrativa chilena. Santiago de Chile: Ediciones Universidad Alberto Hurtado, 2018.

Arfuch, Leonor. El espacio biográfico. Dilemas de la subjetividad contemporánea. México D.F: Fondo de Cultura Económica, 2002. . La vida narrada. Memoria subjetividad y política. Córdoba: Eduvim, 2018.

Basile, Teresa. Infancia. La narrativa argentina de HIJOS. Córdoba: Eduvim, 2019.

Basile, Teresa, y Miriam Chiani, eds. Voces de la violencia. Avatares del testimonio en el Cono Sur. Buenos Aires: EDULP, 2020.

Butler, Judith. Marcos de guerra. Las vidas lloradas. México, D.F: Paidós, 2010.

Cánovas, Rodrigo. Escenas autobiográficas chilenas. Santiago de Chile: Ediciones Universidad Católica de Chile, 2019.

Carrasquer, Luna. "Memoria de la dictadura, hibridez y ambiguedad en $L a$ dimensión desconocida, de Nona Fernández." Taller de Letras.67 (2020): 22-40.

Dällenbach, Lucien. El relato especular. Madrid: Visor, 1991.

Didi-Huberman, George. Cuando las imágenes toman posición. El ojo de la historia 1. Madrid: A. Machado Libros, 2008. . La imagen superviviente. Historia del arte y tiempo de los fantasmas según Aby Warburg. Madrid: Abada Editores, 2009. . La supervivencia de las luciérnagas. Madrid: Abada Editores, 2012.

Espinosa, Patricia. "Patricia Espinosa: "Ningún arte, menos la literatura, va a ser el mismo después de este estallido"." Tendencias. Ed. Palma, Tamy. Santiago de Chile: La Tercera, 08 e noviembre, 2019.

Felman, Shoshana, and Dori Laub. Testimony. Crises of Witnessing in Literature, Pscychoanalysis, and History. New York: Routledge, 1992.

Fernández, Nona. Chilean Electric. Santiago de Chile: Alquimia, 2015. . La dimensión desconocida. Santiago de Chile: Penguin Random House, 2016. 
. Space Invaders. 2013. La Habana: Fondo Editorial Casa de Las Américas, 2016.

García Canclini, Néstor. Culturas híbridas: Estrategias para entrar y salir de la modernidad. Paidós, 2001.

Garramuño, Florencia. La experiencia opaca. Literatura y desencanto. Buenos Aires: Fondo de Cultura Económica, 2009.

Genette, Gérard. Metalepsis. De la figura a la ficción. Buenos Aires: Fondo de Cultura Ecnonómica, 2004.

Lazzara, Michael. Civil Obedience. Complicity and Complacency in Chile since Pinochet. Wisconsin: The University of Wisconsin Press, 2018.

Martínez Rubio, José. Las formas de la verdad: investigación, docuficción y memoria en la novela hispánica (2000-2015). Barcelona: Anthropos Editorial, 2015.

Massey, Doreen. "La filosofía y la política de la espacialidad: algunas consideraciones." Pensar este tiempo. Espacios, afectos, pertenencias. Ed. Arfuch, Leonor. Buenos Aires: Paidós, 2005. 103-27.

Miranda Acuña, Daniel. "Los ojos del estallido". https://www.youtube.com/watch?v=UTmPPYwtpdU

Miranda Mora, Macarena. "Superposición y coalescencia, el mecanismo titilante en la narrativa de Nona Fernández." Romanica Olomucensia 31.2 (2019): 255-68.

Memoria viva. Archivo digital de las Violaciones a los Derechos Humanos por la Dictadura Militar en Chile (1973-1990).

https://memoriaviva.com/nuevaweb/criminales/criminales-v/valenzuelamorales-andres-antonio/

Nancy, Jean-Luc. La comunidad desobrada. Trans. Perera, Pablo. Madrid: Arena Libros, 2001.

Pastén, J. Agustín "El presente del pasado en las novelas de Nona Fernández." Mapocho. Revista de Humanidades Ediciones Biblioteca Nacional.88 (2020): 124-44.

Rancière, Jacques. El espectador emancipado. Buenos Aires: Manantial, 2010. . Sobre políticas estéticas. Barcelona: Unversitat Autónoma de Barcelona, 2006.

Salomon Gehard, José. Falso subalterno. Testimonio y ficción en la narrativa chilena de postdictadura. Santiago de Chile: Piso Diez Ediciones, 2020.

\footnotetext{
(cc) EY

New articles in this journal are licensed under a Creative Commons Attribution 4.0 United States License.

ULLS D-Sonke This site is published by the University Library System, University of Pittsburgh as part of its D-Scribe Digital Publishing Program and is cosponsored by the University of Pittsburgh Press.
} 